\title{
The effect of adhesive surface with porcelain sintering and two silane coupling agents on the adhesive properties of zirconia
}

\author{
Man Zhao ${ }^{1 \#}$, Yaqi Zheng ${ }^{1 "}$, Jia-Feng Zhang ${ }^{2}$, Xing Ou$^{2}$, Xing Gao ${ }^{3}$, Bao Zhang ${ }^{2}$, Yang Cao ${ }^{4}$ \\ ${ }^{1}$ Department of Stomatology, The People's Hospital of Longhua Shenzhen, Shenzhen, China; ${ }^{2}$ National Engineering Laboratory for High Efficiency \\ Recovery of Refractory Nonferrous Metals, School of Metallurgy and Environment, Central South University, Changsha, China; ${ }^{3}$ Center of \\ Stomatology, Xiangya Hospital of Central South University, Changsha, China; ${ }^{4}$ Medical Equipment Department, Xiangya Hospital of Central South \\ University, Changsha, China \\ Contributions: (I) Conception and design: M Zhao, Y Zheng; (II) Administrative support: M Zhao, Y Cao; (III) Provision of study materials or \\ patients: M Zhao, Y Zheng; (IV) Collection and assembly of data: M Zhao, Y Cao; (V) Data analysis and interpretation: M Zhao, Y Cao; (VI) \\ Manuscript writing: All authors; (VII) Final approval of manuscript: All authors. \\ \#These authors contributed equally to this work and should be considered as co-first authors. \\ Correspondence to: Yang Cao. Medical Equipment Department, Xiangya Hospital of Central South University, Changsha 410008, China. \\ Email: caoyangbme@163.com.
}

Background: To explore the effect of adhesive surface with porcelain sintering and different silane coupling agents on adhesive properties of zirconia ceramics.

Methods: Zirconia blocks ( $n=72)$ were randomly divided into two large groups $(n=36)$ according to whether the adhesive surface was treated with sintered porcelain: $\mathrm{N}$ (no porcelain sintering), $\mathrm{P}$ (porcelain sintering). Then, according to different silane coupling agents, each group was randomly divided into three small groups, six small groups in total $(\mathrm{n}=12)$ : NN (no porcelain sintering and agent), NM (no porcelain sintering + Monobond-S), NC (no porcelain sintering + Clearfil Repair); PN (porcelain sintering + no agent), PM (porcelain sintering + Monobond-S), PC (porcelain sintering + Clearfil Repair). After surface treatment, RelyX Unicem Cement was used to make ceramic-resin bonding specimens. Then, each of the six small groups was randomly divided into two subgroups; shear bond strength (SBS) was tested and bond failure mode was analyzed before and after thermal cycling 5,000 times.

Results: (I) SBS analysis: the SBS values of the P groups were significantly higher than those of the $\mathrm{N}$ groups $(\mathrm{P}<0.05)$. The groups treated with silane coupling agents showed higher SBS values than the control group $(\mathrm{P}<0.05)$, and the $\mathrm{PC}$ groups showed the highest $\mathrm{SBS}$ values $(\mathrm{P}<0.05)$. The $\mathrm{SBS}$ of each group was significantly decreased after thermal cycling $(\mathrm{P}<0.05)$. (II) The microcharacteristics under scanning electron microscopy and energy spectrum analysis: the ceramic blocks being treated by porcelain sintering showed more roughness than the control group. A large amount of silicon ( $\mathrm{Si}$ ) appeared on the surface of the ceramic blocks after porcelain sintering.

Conclusions: (I) Treating the adhesive surface by porcelain sintering can improve the bonding strength between zirconia and RelyX Unicem Cement, and the effect was better in conjunction with silane coupling agent. (II) The two kinds of silane coupling agent (Monobond-S, Clearfil Repair) can improve the bonding strength between zirconia and resin cement. The effect of Clearfil Repair is better than that of Monobond-S. (III) Thermal cycling had a significant adverse effect on SBS between zirconia and RelyX Unicem Cement. Clearfil Repair is helpful in improving the durability of zirconia bonding strength.

Keywords: Zirconia; porcelain sintering; silane coupling agent; bonding strength; silica coating

Submitted Nov 22, 2021. Accepted for publication Jan 18, 2022.

doi: $10.21037 / \mathrm{atm}-22-72$

View this article at: https://dx.doi.org/10.21037/atm-22-72 


\section{Introduction}

The evolution of digital technologies in stomatology over the past few years has further promoted the extensive application of zirconia ceramics in prosthodontics $(1,2)$. However, since zirconia ceramics are free of silica-phase components, it is impossible for hydrofluoric acid (HF), phosphoric acid $\left(\mathrm{H}_{3} \mathrm{PO}_{4}\right)$ and other acids to etch zirconia substrate structures and impossible to achieve strong chemical bonding with conventional silane coupling agents, which is also an essential aspect of surface bonding with zirconia ceramics that is not as good as with cast ceramics (3). Current surface treatment techniques improving the bonding properties of zirconia ceramics include sandblasting $(4,5)$, laser treatment (6), hot acid etching (7), silica coating (8), etc. The best-known technique to improve the bonding properties of zirconia surfaces is silica coating, where silicon-phase components are coated on zirconia surfaces by various methods to modify the surface and effectively improve chemical retention. The existing silica coating techniques include tribochemical silica coating $(9,10)$, selective osmotic etching (11), plasma deposition (12), etc. However, such silica coating techniques are complex to perform, and the relevant equipment is expensive, making it difficult to generalize these coating techniques in the clinical setting. Additionally, the stability between silica coating and the porcelain block surface remains controversial. Ozcan et al. found that the combination of tribological silica coating with silane coupling agent-assisted treatment effectively improved the bonding properties (13) of zirconia ceramics; however, this method relies on sandblasting and is thus prone to the aforementioned microcracking. Furthermore, the bonding strength between silica coating and the porcelain block surface is controversial. Nishigawa found that the silica phase attached to the zirconia porcelain surface is easily dislodged in large quantities during cleaning (14). Cattani Lorente et al. (15) also investigated and found that the silica coating mass fraction would decrease by at least $30 \%$ after ultrasonic cleaning.

The porcelain sintering for prosthesis surfaces is principally performed to have glass-ceramic powder sintered and fused to the outer surface of the prosthesis for aesthetically pleasing prosthetic treatment; moreover, the porcelain layer resists occlusal forces without falling off during chewing, which suggests significantly strong bonding between the porcelain layer and the zirconia ceramics. In veneering porcelain sintering, we can silica coating on the adhesive surface at the same time, without other technology and equipment. Silane coupling agents were widely used on the oral prosthesis surface to improve the bond strength between the prosthesis and the resin adhesive, by forming a chemical bonding force. Silane coupling agents can wet the prosthesis surface, which was conducive to the flow and penetration of the adhesive.

In this study, to improve the above-noted silica coating technique that is prone to detachment, the less strong and complex silica coating technique was replaced by firmly coating the adhesive surface of zirconia ceramics with a simple porcelain sintering technique using $\mathrm{SiO}_{2}$-rich glassceramic powders and combining them with different silane coupling agents to evaluate the effects of the new silica coating technique on the bonding properties of zirconia ceramics. As an important research indicator, the shear force is the most frequent force sustained by the prosthesis during oral physiological activities. The shear bond strength (SBS), refers to the ability of the material to withstand the shear force, namely the maximum shear stress parallel to the test interface $(\mathrm{MPa})$, was chosen to measure the bonding strength.

\section{Methods}

\section{Preparation of zirconia porcelain block}

The zirconia porcelain cake (Upcera Biochemicals Co., Ltd., Liaoning, China) was cut into 72 small porcelain blocks with an area of $8.75 \mathrm{~mm} \times 8.75 \mathrm{~mm}$ and a thickness of $2.5 \mathrm{~mm}$ using a slow cutter. The 72 blocks were sintered in a dental programmable sintering furnace at a constant temperature of $1,450{ }^{\circ} \mathrm{C}$ for $12 \mathrm{~h}$; the sintering shrinkage rate of Upcera's zirconia porcelain blocks was $20 \%$, and the final volume of the sintered blocks was $7 \mathrm{~mm} \times 7 \mathrm{~mm} \times 2 \mathrm{~mm}$. On the grinding and polishing machine (500 rpm), the surface of the sintered zirconia porcelain block was sanded and polished in sequence using \#200, \#600 and \#1000 SiC sandpaper under running water cooling conditions. Upon completion of polishing, the zirconia porcelain block was ultrasonically cleaned using distilled water for 5 min and blown dry using oil-free compressed air. Then, the surface of the zirconia porcelain block was abrasively blasted using a pen-type sand blaster. The zirconia porcelain surface was treated by vertical sandblasting for $10 \mathrm{~s}$ using $110 \mu \mathrm{m}$-diameter $\mathrm{Al}_{2} \mathrm{O}_{3}$ particles at a constant pressure of $0.4 \mathrm{MPa}$, with a distance of $10 \mathrm{~mm}$ from the nozzle to the surface of the porcelain block. Lastly, the sand-blasted porcelain blocks were ultrasonically cleaned again for $5 \mathrm{~min}$, blown dry and then randomly divided into two general groups, i.e., the porcelain sintering group $(n=36)$ and the no porcelain sintering group $(n=36)$. 


\section{Veneering of porcelain block surface}

A polyester film mold with a square hole in the middle and a thickness of $100 \mu \mathrm{m}$ was placed on the surface of the clean porcelain block in the porcelain sintering group. Based on the material blending requirements, IPS e.max cream porcelain powder (Ivoclar Vivadent AG, Principality of Liechtenstein) was mixed with distilled water in a volume ratio of $1: 1$; the blended IPS e.max Ceram porcelain powder slurry was coated on the sand-blasted surface of the porcelain block in the polyester film mold and sintered in the all-porcelain vacuum porcelain oven following the requirements of porcelain powder sintering treatment. The sintered porcelain blocks were cleaned with $75 \%$ alcohol solution for $15 \mathrm{~min}$, then ultrasonically cleaned with distilled water for $5 \mathrm{~min}$ and blown dry for later use. Sintering process: The blocks were predried for $5 \mathrm{~min}$. The initial temperature was set to $403{ }^{\circ} \mathrm{C}$ and then raised with a $40{ }^{\circ} \mathrm{C} / \mathrm{min}$ gradient after the temperature was held for 4 min; vacuum sintering was carried out after the temperature reached $450{ }^{\circ} \mathrm{C}$, and the temperature was then raised to and maintained at $750^{\circ} \mathrm{C}$ for $1 \mathrm{~min}$. At the end, the blocks cooled down naturally to room temperature.

\section{Preparation of bonding specimens}

\section{Fabrication of composite resin sheets}

A mold of $4 \mathrm{~mm} \times 4 \mathrm{~mm} \times 2 \mathrm{~mm}$ in size was fabricated using a silicone impression material (3M ESPE, USA), placed on a clean and dry glass sheet, filled with FS-1 lightcured resin (Shanghai Eryi Zhangjiang Biomaterial Co., Ltd., Shanghai, China), and cured for $20 \mathrm{~s}$ using a light emitting diode (LED) light curing lamp to make 66 square resin blocks of $4 \mathrm{~mm} \times 4 \mathrm{~mm} \times 2 \mathrm{~mm}$ in size.

\section{Grouping and surface treatment of porcelain sheets}

The 72 porcelain blocks were divided into porcelain sintering group $(\mathrm{P})$ and no porcelain sintering group $(\mathrm{N})$ depending on whether the surfaces of the zirconia blocks were veneer-sintered. The 36 samples $(n=36)$ of each general group were divided into three groups of 12 samples each $(\mathrm{n}=12)$ according to treatment with different silane coupling agents before bonding on the block surface (Figure 1, Table 1):

No porcelain sintering group $(\mathrm{N})$ /porcelain sintering group $(\mathrm{P})$ :

(I) NN group/PN group: the surfaces were not treated with silane coupling agents;

(II) NM group/PM group: the surfaces were treated with Monobond-S (Ivoclar Vivadent, Germany) by the following method: Monobond-S was applied evenly to the porcelain sheets with a small disposable brush, treat for $60 \mathrm{~s}$ and then blow dried for $5 \mathrm{~s}$ using $0.3 \mathrm{MPa}$ oil-free compressed air;

(III) NC group/PC group: the surfaces were treated with Clearfil Repair (Kuraray Medical, Tokyo, Japan) by the following method: One drop of porcelain treatment agent and one drop of bonding pretreatment agent were mixed on a blending plate at a $1: 1$ ratio. The mixture was evenly applied to the surfaces of porcelain blocks with a small special disposable brush, treated for $5 \mathrm{~s}$ and then blow dried for $5 \mathrm{~s}$ using $0.3 \mathrm{MPa}$ oil-free compressed air.

At the end of the surface treatment discussed above, one sample from each group was randomly selected for surface scanning electron microscopy (SEM) and energy spectroscopy, while the remaining 11 samples were made into bonded specimens.

\section{Fabrication of bonded specimens}

A single-sided bonding tape with a square hole in the middle measuring $4 \mathrm{~mm} \times 4 \mathrm{~mm}$ was adhered to the center of the adhesive surface of the zirconia porcelain block, while the edges of the square hole were parallel to the edges of the porcelain blocks to restrict the bonding area. In addition, Rely X Unicem Cement (3M ESPE, USA) capsules were activated for $4 \mathrm{~s}$ in the activator in strict accordance with the manufacturer's instructions and then shaken for $10 \mathrm{~s}$ on a silver-mercury blender. Equal amounts of Rely X Unicem Cement were squeezed into a limited area of each porcelain block treatment surface. The prepared resin blocks were bonded in place on the surfaces of porcelain blocks. A 750-g weight was placed on the bonded resin block to control the bonding pressure and bonding agent thickness. After $1 \mathrm{~min}$, the spilled bonding agent was removed from the periphery of the resin block. The resin blocks were then subjected to circular lighting by LED light curing lamp for $40 \mathrm{~s}$. There were 66 bonded specimens in total.

All bonded specimens were left to stand at room temperature for $30 \mathrm{~min}$ after fabrication, and one bonded specimen per group was randomly selected for bonding interface observation, leaving 10 bonded specimens in each group. 


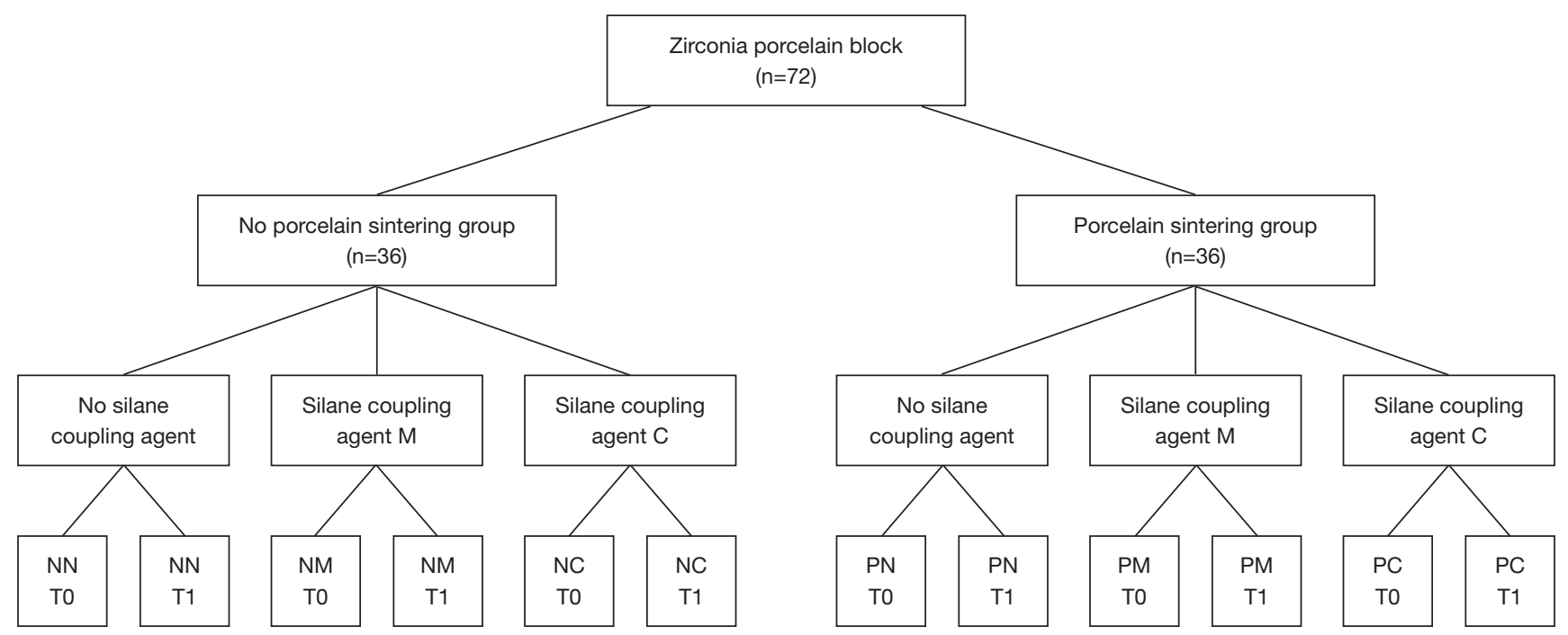

Figure 1 Flow chart of experimental grouping. T0, 0 thermal cycles; T1, 5,000 thermal cycles; NN, no porcelain sintering and agent; NM, no porcelain sintering + Monobond-S; NC, no porcelain sintering + Clearfil Repair; PN, porcelain sintering + no agent; PM, porcelain sintering + Monobond-S; PC, porcelain sintering + Clearfil Repair.

Table 1 Profile of each experimental group, porcelain sintering, and type of silane coupling agent

\begin{tabular}{lcc}
\hline Group & Porcelain sintering & Silane coupling agent \\
\hline NN & No & No \\
NM & No & Monobond-S \\
NC & No & Clearfil Repair \\
PN & Porcelain & No \\
PM & Porcelain & Monobond-S \\
PC & Porcelain & Clearfil Repair \\
\hline
\end{tabular}

$\mathrm{NN}$, no porcelain sintering and agent; NM, no porcelain sintering + Monobond-S; NC, no porcelain sintering + Clearfil Repair; $\mathrm{PN}$, porcelain sintering + no agent; PM, porcelain sintering + Monobond-S; PC, porcelain sintering + Clearfil Repair.

\section{SEM and energy spectroscopy}

\section{Surface morphological observation and elemental analysis}

After surface treatment, one sample (six in total) was randomly selected from each group of specimens and gold-sprayed in an automatic gold sprayer for $5 \mathrm{~min}$. Then, the gold-sprayed sample was subjected to SEM for observation of the surface morphology at a voltage of $20 \mathrm{kV}$ and a magnification of $500 \times$ and $1,000 \times$, while energy spectrum analysis (energy dispersive spectrometry, EDS) was performed on the surface of each sample to analyze the elemental composition and content of the surface.

\section{Bonding interface observation}

After the bonded specimens had been left to stand at room temperature for $30 \mathrm{~min}$, one specimen (six in total) was randomly chosen from each group, and the porcelain-resin composite was cut open longitudinally using a slow cutter. The longitudinal section of the bonded specimen was sanded in sequence using \#600 and \#1000 sandpaper and then kept in distilled water for $5 \mathrm{~min}$ for ultrasonic cleaning. The dried specimen was gold-sprayed in an automatic gold sprayer for $5 \mathrm{~min}$, and the longitudinal section of porcelain-resin bonded interface was observed by SEM at a magnification of 2,000x.

\section{Simulated aging of bonded specimens}

The bonded zirconia porcelain-resin blocks were left to stand at room temperature for $30 \mathrm{~min}$ and then kept in a thermostatic distilled water bath at $37^{\circ} \mathrm{C}$ for $24 \mathrm{~h}$. Five bonded specimens from each group were randomly selected for shear measurement on a Material Test Systems (MTS) fatigue tester, while the remaining five bonded specimens were subjected to 5,000 thermal cycles in a water bath (one $70 \mathrm{~s}$ thermal cycle consisted of soaking at $5{ }^{\circ} \mathrm{C}$ for $30 \mathrm{~s}$, removing and draining for $5 \mathrm{~s}$, soaking in a $55^{\circ} \mathrm{C}$ water bath for $30 \mathrm{~s}$, and then removing and draining for $5 \mathrm{~s}$ ) to determine the shear force after the simulated aging. 


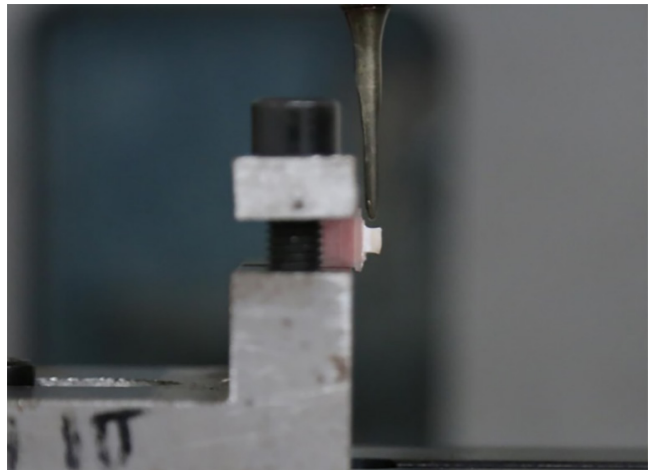

Figure 2 Shear force test.

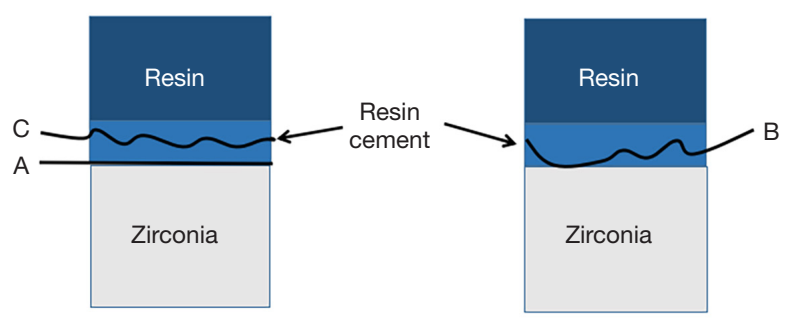

Figure 3 Bond failure types of the no porcelain sintering group. A, adhesive failure; B, mixed failure; C, cohesive failure.

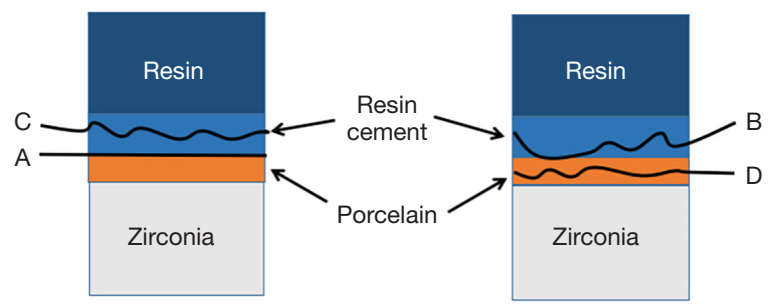

Figure 4 Bond failure types of the porcelain sintering group. A, adhesive failure; B, mixed failure; C, cohesive failure; D, porcelain failure.

\section{Shear strength test}

The specimen was embedded based on loading requirements of the MTS fatigue tester and placed on the tester through a special fixture, with the loader in contact with the resin block at the center of the block (Figure 2). The loading direction was parallel to the porcelain adhesive surface. The loading speed of the loader was $0.5 \mathrm{~mm} / \mathrm{min}$, and the maximum load was $1,000 \mathrm{~N}$. The loader was kept out of contact with the porcelain block and the bonding agent during measurement, and the maximum shear force $(\mathrm{F})$ was documented for each loaded resin block until it fell off. The shear strength was calculated by dividing the maximum loaded shear force at failure by the bonding area, i.e., $\mathrm{SBS}=\mathrm{F} / \mathrm{S}$, in $\mathrm{MPa}$, where $\mathrm{F}$ represents the maximum shear force $(\mathrm{N})$ when the resin block is separated from the zirconia porcelain block. $\mathrm{S}$ denotes the bonding area, i.e., $4 \times 4 \mathrm{~mm}^{2}$.

\section{Bond types}

The bonded surface of shear-failed zirconia porcelain block was observed under a $3 \mathrm{D}$ video microscope at a magnification of $30 \times$ to identify and calculate statistics for the types of bonding interface failure (Figures 3,4).

A. Adhesive failure: failure at the contact interface between the zirconia porcelain adhesive surface and the bonding agent; that is, the surface of the zirconia porcelain shows almost no bonding agent residue under the microscope.

B. Mixed failure: interface failure includes cohesive failures and adhesive failures; that is, the zirconia porcelain adhesive surface was not completely covered by the bonding agent under the microscope.

C. Cohesive failure: interface failure occurs in the bonding agent; that is, the zirconia porcelain adhesive surface is almost completely covered by the bonding agent under the microscope.

D. Porcelain failure: interface failure occurs in the porcelain layer of veneer; that is, porcelain layer failure or peeling is observed under the microscope.

\section{Data processing and statistical analysis}

All test data were processed using the SPSS 25.0 package, and a three-way ANOVA was performed on the shear strength data of each experimental group to examine whether there was an interaction between the factors. If an interaction occurred $(\mathrm{P}<0.05)$, a one-way ANOVA was performed on the sample data and combined with the LSD test for analysis. If an interaction did not occur $(\mathrm{P}>0.05)$, an independent sample $t$-test was selected for analysis; the test level was $\alpha=0.05$, and differences between the compared data were considered statistically significant when $\mathrm{P}<0.05$.

\section{Results}

\section{Surface morphological observation}

After surface treatment of the porcelain block, the adhesive surface was observed via SEM at 500x and 

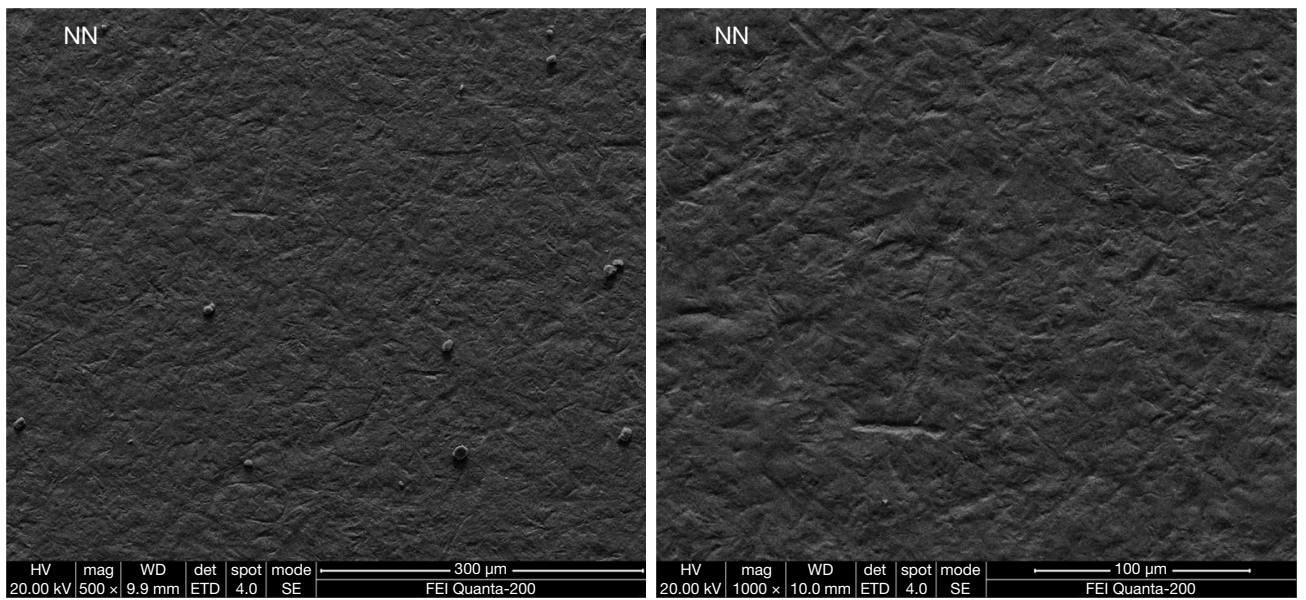

Figure 5 SEM image of the sandblasting group with no porcelain sintering. SEM, scanning electron microscopy; NN, no porcelain sintering and agent.
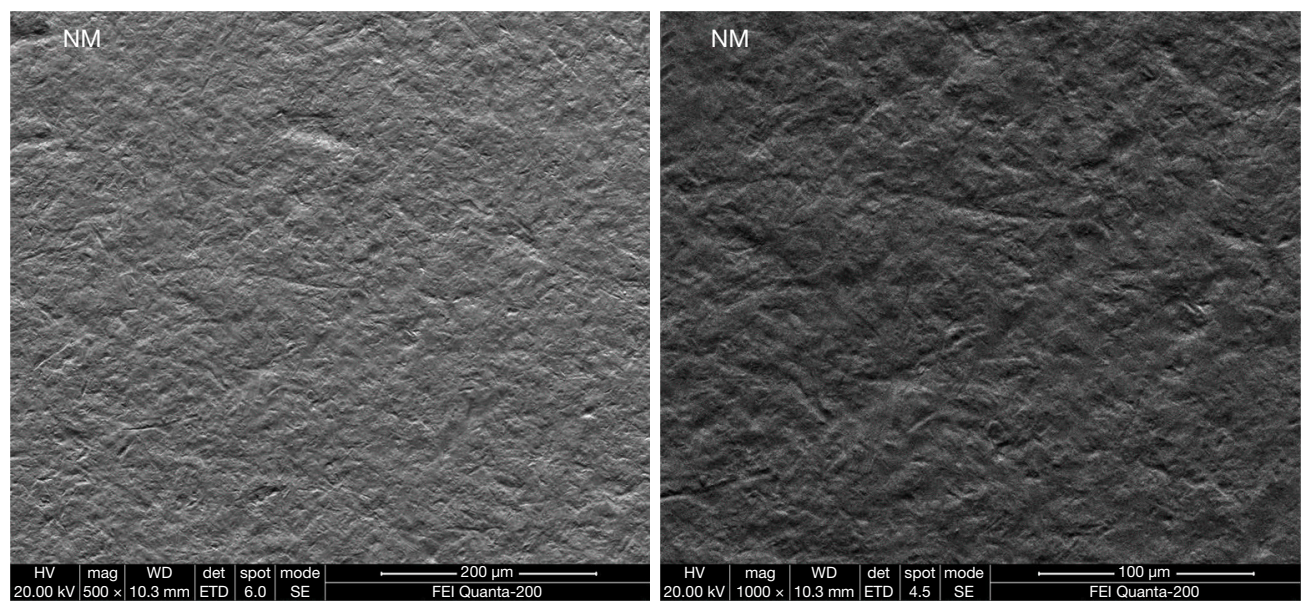

Figure 6 SEM image of the Monobond-S treatment group with no porcelain sintering. SEM, scanning electron microscopy; NM, no porcelain sintering + Monobond-S.

$1,000 \times$ magnification, and the results are as follows. NN group: Uneven and rough surface; cavity-type cracks with sharp perimeters; occasional microcracks and residual $\mathrm{Al}_{2} \mathrm{O}_{3}$ particles (Figure 5) caused by sandblasting. NM group: The surface was still rough and uneven, but it was less bumpy than in the NN group, with shallower microcracks and reduced sharpness of the perimeter (Figure 6). NC group: A membrane-like substance covering the surface was observed, with uneven structures and microcracks barely visible (Figure 7). PN group: extremely rough surface with a large number of irregularly distributed pores visible; extensive sharp bumps were observed between the pores (Figure 8). PM group: the surface was still visible with a large number of pores, which were shallower and more regular than in the $\mathrm{PN}$ group. The sharp bumps around the pores were blunt (Figure 9). PC group: A distinct membranous covering of material was visible on the surface; the pores were markedly shallow and almost invisible. Occasional blunt bumps were visible (Figure 10).

\section{Surface energy spectrum analysis}

The elemental composition and peak energy spectra of each group of porcelain blocks were summarized after surface treatment (Figure 11). As shown in the figures, the $\mathrm{NN}$ group with no porcelain sintering contains oxygen $(\mathrm{O})$, zirconia (Zr), hafnium (Hf), yttrium (Y) and gold 

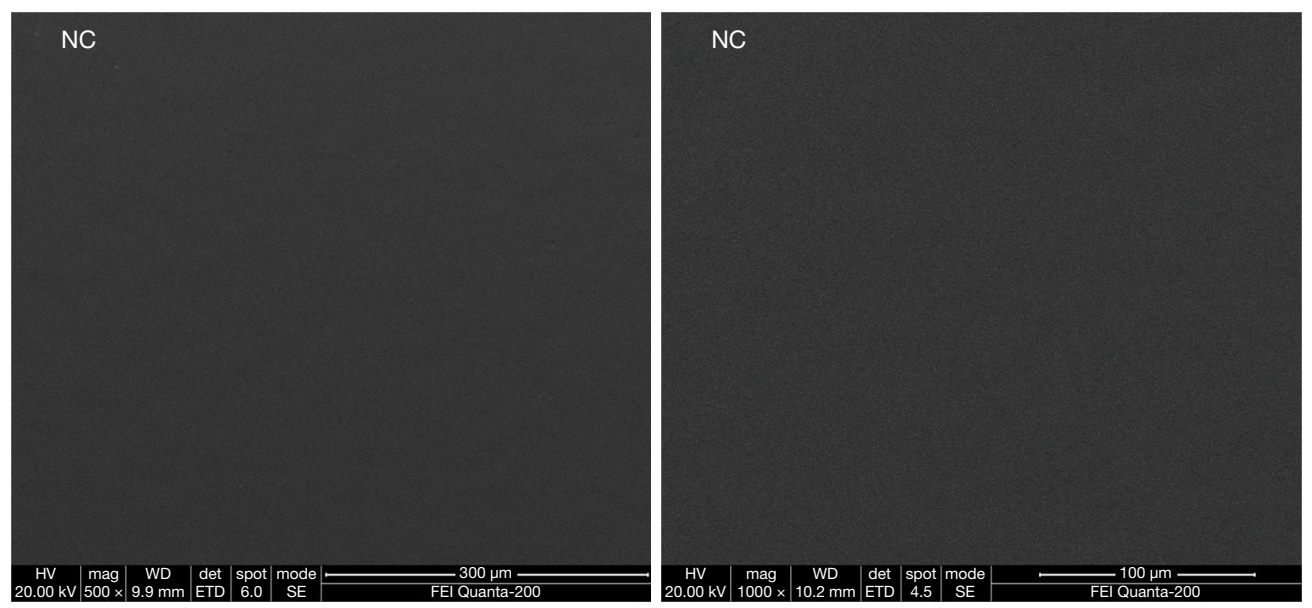

Figure 7 SEM image of the Clearfil Repair treatment group with no porcelain sintering. SEM, scanning electron microscopy; NC, no porcelain sintering + Clearfil Repair.
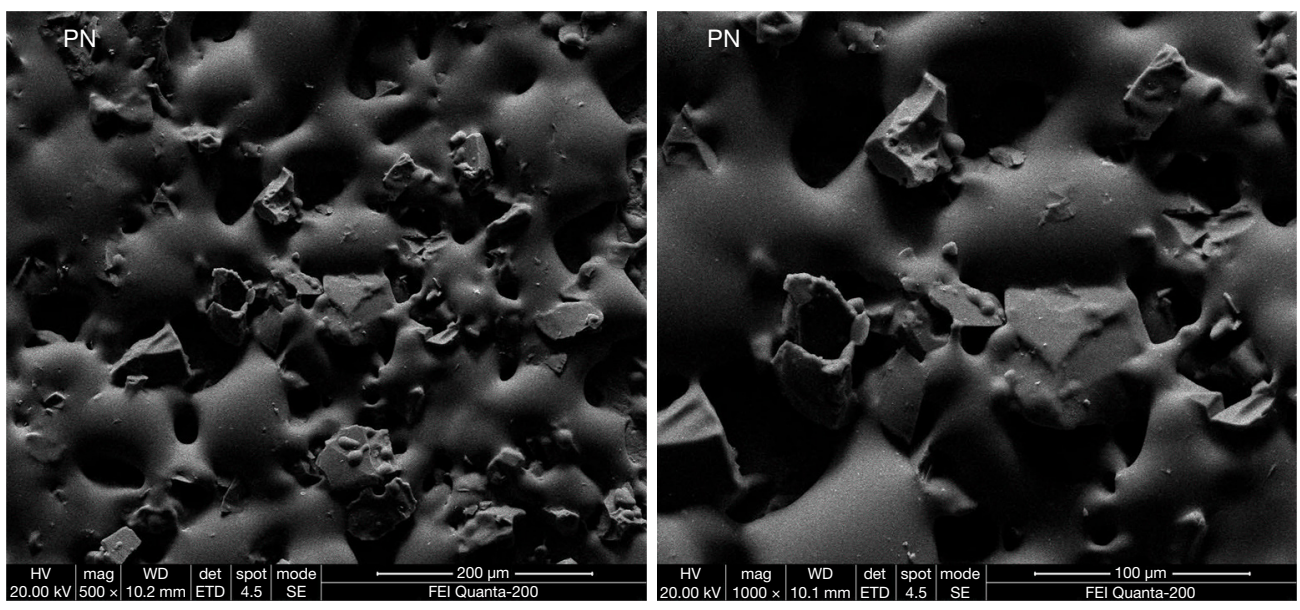

Figure 8 SEM image of the control group with porcelain sintering. SEM, scanning electron microscopy; PN, porcelain sintering + no agent.

(Au), among which $\mathrm{Zr}$, Hf and $\mathrm{Y}$ are from the elemental composition of the zirconia porcelain block itself, and Au is from the gold powder sprayed before the SEM scan, while the surface aluminum (Al) content is $0.02 \%$ (extremely low content). Both the NM and NC groups have carbon (C) and silicon ( $\mathrm{Si}$ ) in the elemental composition of the surface of the porcelain block, and the content of C (49.51\%) and $\mathrm{Si}(6.31 \%)$ in the NC group is higher than the content of $\mathrm{C}(2.01 \%)$ and $\mathrm{Si}(1.39 \%)$ in the NM group. Moreover, the NC group also contains $\mathrm{P}$, with a content of $1.15 \%$.

After porcelain sintering $(\mathrm{P})$, all groups are missing elements such as $\mathrm{Zr}$, Hf and $\mathrm{Y}$ on the peak energy spectrum graphs, but the elemental composition of the IPS e.max Ceram porcelain powder includes sodium $(\mathrm{Na})$, aluminum
(Al), silicon $(\mathrm{Si})$, potassium $(\mathrm{K})$, calcium $(\mathrm{Ca})$, titanium $(\mathrm{Ti})$, and zinc ( $\mathrm{Zn})$. Si has the highest elemental content, with a percentage of $29.25 \%$ in the $\mathrm{PN}$ group, $30.12 \%$ in the PM group, and $12.17 \%$ in the PC group. C is found in the elemental composition of the porcelain block surfaces in the $\mathrm{PM}$ and PC groups; as in the $\mathrm{NC}$ group, $\mathrm{P}$ is also present on the surface in the PC group.

\section{Bonding strength test}

The statistical results of the shear strength data before and after the thermal cycling treatment for each experimental group are shown in Table 2 and Figure 12. A three-way ANOVA was first performed on the experimental data 

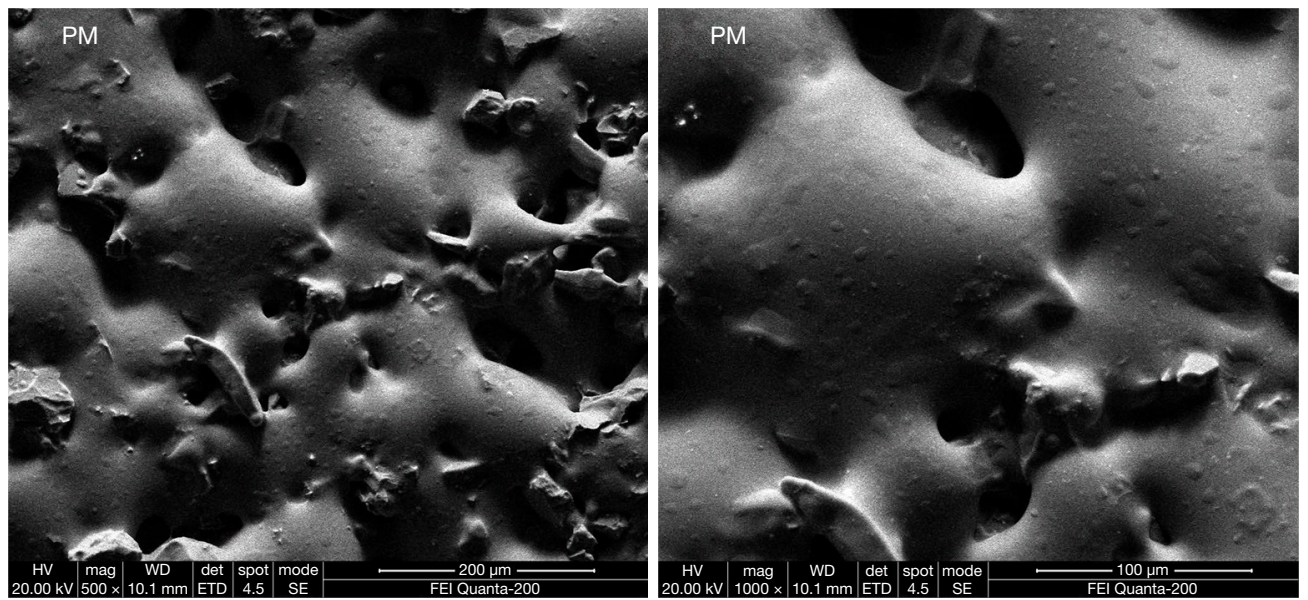

Figure 9 SEM image of the Monobond-S treatment group with porcelain sintering. SEM, scanning electron microscopy; PM, porcelain sintering + Monobond-S.
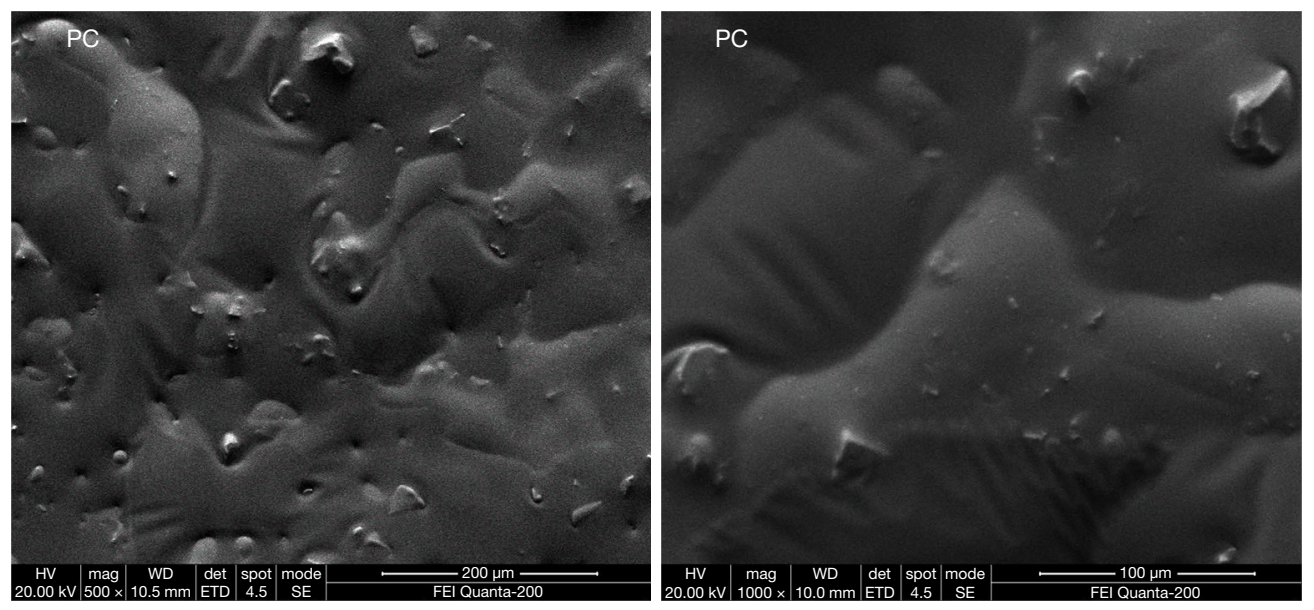

Figure 10 SEM image of the Clearfil Repair treatment group with porcelain sintering. SEM, scanning electron microscopy; PC, porcelain sintering + Clearfil Repair.

acquired (Table 3). The three factors for the experiment were as follows; A: porcelain sintering of the adhesive surface; B: silane coupling agent; C: thermal cycling. According to the ANOVA results, $\mathrm{P}<0.05$ for the porcelain sintering of zirconia porcelain block adhesive surface, for the treatment with silane coupling agents, and the thermal cycling treatment, indicating that all three treatment factors had a significant effect on the bond strength between zirconia ceramic and the bonding agent RelyX Unicem. The interactions between the factors were also analyzed; $\mathrm{P}>0.05$ between thermal cycling and porcelain sintering, while $\mathrm{P}>0.05$ between thermal cycling and silane coupling agent, which suggests there were no interactions between thermal cycling and porcelain sintering or between thermal cycling and silane coupling agent. However, $\mathrm{P}<0.05$ between porcelain sintering and silane coupling agent, demonstrating an interactive effect between sintering and treatment with a silane coupling agent.

Due to the interaction between porcelain sintering and silane coupling agent, a one-way ANOVA combined with least significant difference (LSD) statistical methods was required for each factor. First, porcelain sintering was controlled to analyze the silane coupling agent factor (Table 4). In both the porcelain sintering group $(\mathrm{P})$ and the no porcelain sintering group $(\mathrm{N})$, the shear strength in the silane coupling agent-treated group was significantly higher 

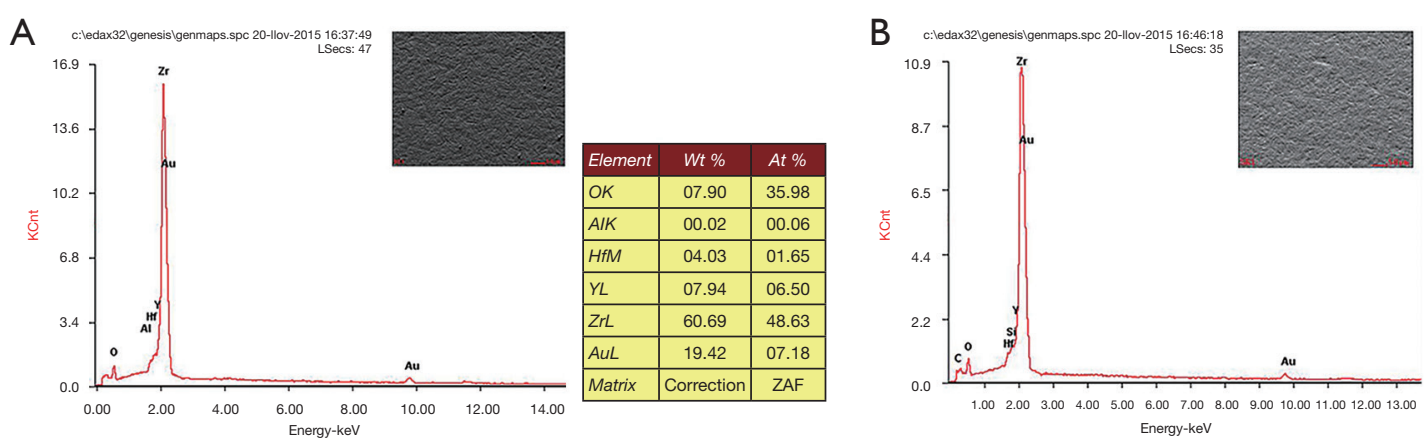

\begin{tabular}{|l|c|c|}
\hline Element & Wt \% & At \% \\
\hline CK & 02.01 & 01.71 \\
\hline OK & 07.93 & 35.00 \\
\hline$H f M$ & 03.24 & 01.28 \\
\hline SiK & 01.39 & 03.50 \\
\hline$Y L$ & 07.95 & 06.31 \\
\hline ZrL & 59.21 & 45.65 \\
\hline AuL & 18.28 & 06.55 \\
\hline Matrix & Correction & ZAF \\
\hline
\end{tabular}
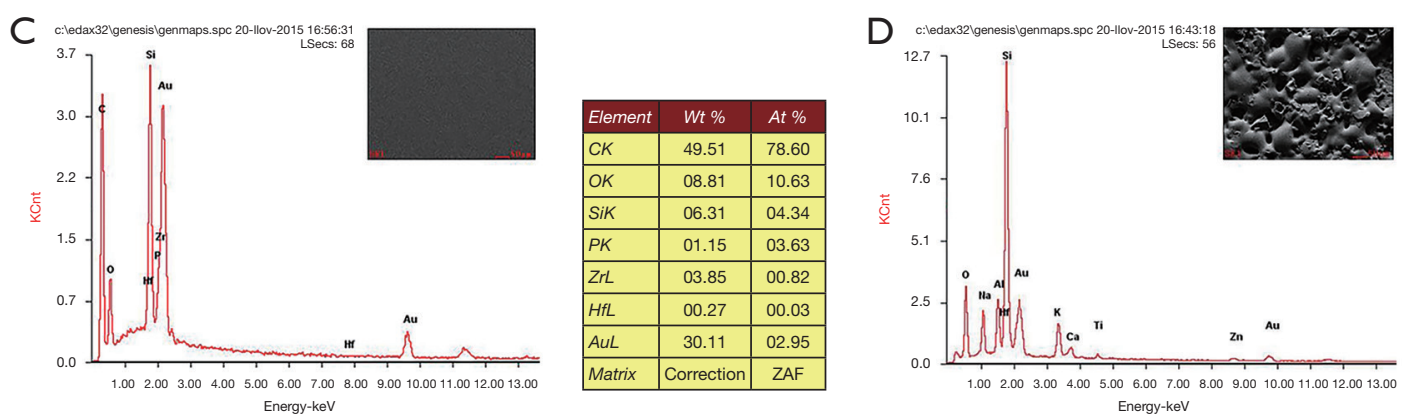

\begin{tabular}{|l|c|c|}
\hline Element & Wt \% & At \% \\
\hline OK & 23.44 & 43.82 \\
\hline Nak & 06.46 & 08.40 \\
\hline AIK & 04.58 & 05.08 \\
\hline SiK & 29.25 & 31.15 \\
\hline KK & 05.18 & 03.97 \\
\hline CaK & 01.56 & 01.16 \\
\hline TiK & 00.73 & 00.46 \\
\hline ZnK & 02.09 & 00.96 \\
\hline AuL & 26.71 & 05.01 \\
\hline Matrix & Correction & ZAF \\
\hline
\end{tabular}
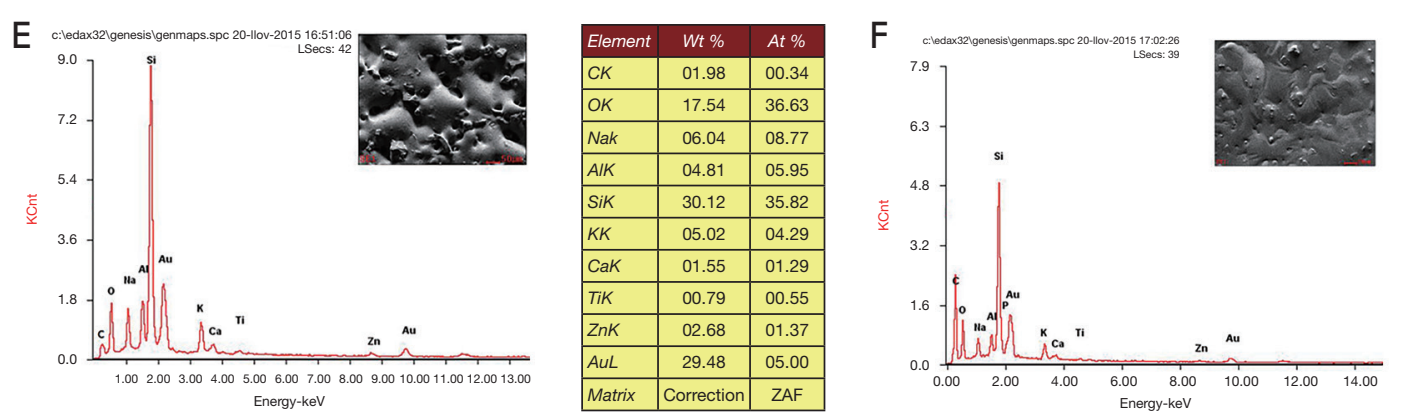

\begin{tabular}{|l|c|c|}
\hline Element & Wt \% & At \% \\
\hline CK & 48.58 & 71.37 \\
\hline OK & 13.63 & 15.03 \\
\hline NaK & 01.93 & 01.48 \\
\hline AIK & 01.46 & 00.96 \\
\hline SiK & 12.17 & 07.65 \\
\hline PK & 00.88 & 00.50 \\
\hline KK & 01.78 & 00.80 \\
\hline CaK & 00.59 & 00.26 \\
\hline TiK & 00.25 & 00.09 \\
\hline ZnK & 01.03 & 00.28 \\
\hline AuL & 17.69 & 01.58 \\
\hline Matrix & Correction & ZAF \\
\hline
\end{tabular}

Figure 11 Energy spectrum analysis of the group after surface treatment. (A) NN group; (B) NM group; (C) NC group; (D) PN group; (E) PM group; (F) PC group. NN, no porcelain sintering and agent; NM, no porcelain sintering + Monobond-S; NC, no porcelain sintering + Clearfil Repair; PN, porcelain sintering + no agent; PM, porcelain sintering + Monobond-S; PC, porcelain sintering + Clearfil Repair.

Table 2 Mean shear strength of each experimental group $(\mathrm{MPa}, \mathrm{n}=5, \mathrm{P}<0.05)$

\begin{tabular}{|c|c|c|c|}
\hline Porcelain sintering & Silane coupling agent & \multicolumn{2}{|c|}{ Bonding strength (MPa) } \\
\hline \multirow[t]{3}{*}{ No porcelain sintering } & NN & $6.35 \pm 0.57$ & $4.54 \pm 0.43$ \\
\hline & NM & $8.71 \pm 0.61$ & $6.47 \pm 0.50$ \\
\hline & NC & $11.71 \pm 0.66$ & $9.43 \pm 0.70$ \\
\hline \multirow{2}{*}{ Porcelain sintering } & PM & $12.46 \pm 0.69$ & $9.49 \pm 0.55$ \\
\hline & $\mathrm{PC}$ & $15.56 \pm 0.74$ & $12.93 \pm 0.83$ \\
\hline
\end{tabular}

NN, no porcelain sintering and agent; NM, no porcelain sintering + Monobond-S; NC, no porcelain sintering + Clearfil Repair; PN, porcelain sintering + no agent; PM, porcelain sintering + Monobond-S; PC, porcelain sintering + Clearfil Repair. 


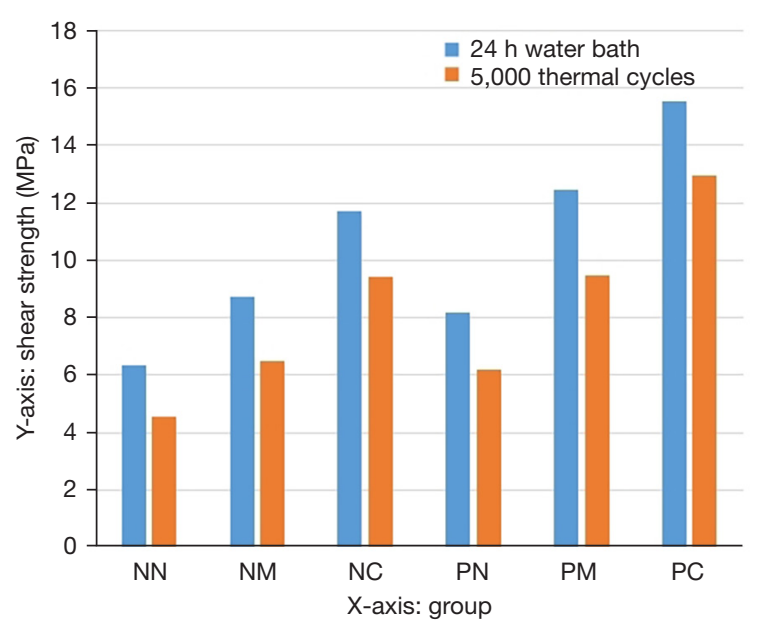

Figure 12 Histogram of the mean shear strength of each experimental group. NN, no porcelain sintering and agent; $\mathrm{NM}$, no porcelain sintering + Monobond-S; NC, no porcelain sintering + Clearfil Repair; PN, porcelain sintering + no agent; $\mathrm{PM}$, porcelain sintering + Monobond-S; PC, porcelain sintering + Clearfil Repair.

than the shear strength of the control group $(\mathrm{P}<0.05)$; the PC group performed significantly better than the PM and $\mathrm{PN}$ groups $(\mathrm{P}<0.05)$, and the $\mathrm{NC}$ group performed significantly better than the $\mathrm{NM}$ and $\mathrm{NN}$ groups $(\mathrm{P}<0.05)$. The shear strength of the porcelain sintering group $(\mathrm{P})$ was significantly higher than the shear strength of the no porcelain sintering group $(\mathrm{N})$ in all experimental groups $(\mathrm{P}<0.05)$. In this respect, $\mathrm{PN}$ was superior to the $\mathrm{NN}$ group, $\mathrm{PM}$ was better than NM group, and PC was superior to the $\mathrm{NC}$ group, all exhibiting significant differences $(\mathrm{P}<0.05)$.

Since there were no interactions between thermal cycling and the other two factors, a two-sample $t$-test analysis of the data before and after thermal cycling for each group demonstrated that shear strength was significantly higher before than after thermal cycling in all groups, with statistically significant differences $(\mathrm{P}<0.05)$.

\section{Type of bond failure}

The bonded surfaces of shear-failed porcelain blocks were observed under a $3 \mathrm{D}$ video microscope and subjected to classified statistics depending on failure types described in the experimental methods. The results are shown in Table 5: Type A is adhesive failure, $\mathrm{B}$ is mixed failure, $\mathrm{C}$ is cohesive failure, and $\mathrm{D}$ is porcelain layer failure. $\mathrm{NN}$ group: before the hot cycle in the water bath, adhesive failure was dominant, and after thermal cycling, all specimens developed adhesive failure. PN group: before thermal cycling, mixed failure was dominant, and after thermal cycling, adhesive failure was dominant. Before thermal cycling, the NM group exhibited principally mixed failure instead of cohesive failure, and after thermal cycling, the NM group showed only one mixed failure, while the PM group showed mainly mixed failure. Although the NC and PC groups were dominated by mixed failure before thermal cycling, both developed cohesive failure, and two cohesive failures appeared in the PC group. A high proportion of mixed failure was found in the NC group after thermal cycling, but one cohesive failure still developed in the PC group. The porcelain layer was not damaged in any of the experimental groups.

\section{Bonding interface observation}

Figures 13 illustrate the SEM $(2,000 x)$ graphs of the bonding interface of each specimen. The NN group (no porcelain sintering) showed obvious and continuous cracks and no obvious resin tags, probably due to mechanical vibration during longitudinal dissection of the specimen and the ultrasonic cleaning before the SEM scan, which shakes off the resin bonding agent; the bonding strength of the NN group is thus not acceptable. Although cracks were visible in the $\mathrm{NM}$ group, they were smaller than in the $\mathrm{NN}$ group and discontinuous. The NC group, in contrast, was much less cracked and exhibited some of the resin bonded tightly to the porcelain block. In the porcelain sintering group $(\mathrm{P})$, the resin tags were mechanically interlocked with the porcelain layer, while in the PN group, large and thick resin tags were embedded in the recessed structure of porcelain layer surface, with a few microcracks. The cracks in the PM group were significantly smaller than those in the PN group, while the bonding interface in the PC group was tightly bonded without obvious cracks.

\section{Discussion}

The results show that the porcelain sintering and silane coupling agent can increase the bonding strength between the resin adhesives and the zirconia ceramics. The SBS in the porcelain sintering group were higher than the no porcelain sintering group. The groups treated with silane coupling agents received higher SBS than control group, with the PC (porcelain sintering + Clearfil Repair) group demonstrating the most significant effect.

Mechanical bonding force and chemical bonding force 
Table 3 Three-way ANOVA

\begin{tabular}{|c|c|c|c|c|c|}
\hline Source of variation & SS & df & MS & $\mathrm{F}$ & $\mathrm{P}$ \\
\hline A (porcelain sintering) & 129.184 & 1 & 129.184 & 312.365 & $<0.05$ \\
\hline B (silane coupling agent) & 371.085 & 2 & 185.542 & 448.639 & $<0.05$ \\
\hline C (thermal cycling) & 80.782 & 1 & 80.782 & 195.331 & $<0.05$ \\
\hline $\mathrm{B}^{*} \mathrm{C}$ & 1.386 & 2 & 0.693 & 1.676 & 0.198 \\
\hline$A^{*} B^{\star} C$ & 0.197 & 2 & 0.099 & 0.238 & 0.789 \\
\hline Error & 19.851 & 48 & 0.414 & & \\
\hline
\end{tabular}

${ }^{*}$, interaction. ANOVA, Analysis of Variance; SS, Sum of squares; df, degree of freedom; MS, Mean square; F, F-statistic; P, Probability.

Table 4 Univariate analysis of treatment with silane coupling agent

\begin{tabular}{llcc}
\hline Porcelain sintering? & Type of silane coupling agent & Mean \pm standard deviation & $\mathrm{F}$ \\
\hline No porcelain sintering & Control group & $5.45 \pm 1.07$ & $7.59 \pm 1.29$ \\
& Group treated with silane coupling agent M & $10.57 \pm 1.36$ \\
& Group treated with silane coupling agent C & $7.19 \pm 1.22$ & 10.05 \\
Porcelain sintering & Control group & Group treated with silane coupling agent M & $10.98 \pm 1.67$ \\
& Group treated with silane coupling agent C & $14.24 \pm 1.57$ \\
\hline
\end{tabular}

M, Monobond-S; C, Clearfil Repair.

Table 5 Statistics on the type of bond failure in each experimental group (pcs; $\mathrm{n}=5$ )

\begin{tabular}{|c|c|c|c|c|c|c|c|c|}
\hline Group & \multicolumn{4}{|c|}{ After $24 \mathrm{~h}$ water storage } & \multicolumn{4}{|c|}{ After 5,000 thermal cycling } \\
\hline NN & 3 & 2 & 0 & 0 & 5 & 0 & 0 & 0 \\
\hline NM & 2 & 3 & 0 & 0 & 4 & 1 & 0 & 0 \\
\hline NC & 1 & 3 & 1 & 0 & 2 & 3 & 0 & 0 \\
\hline $\mathrm{PC}$ & 0 & 3 & 2 & 0 & 2 & 2 & 1 & 0 \\
\hline
\end{tabular}

NN, no porcelain sintering and agent; NM, no porcelain sintering + Monobond-S; NC, no porcelain sintering + Clearfil Repair; PN, porcelain sintering + no agent; PM, porcelain sintering + Monobond-S; PC, porcelain sintering + Clearfil Repair; A, adhesive failure; B, mixed failure; $\mathrm{C}$, cohesive failure; $\mathrm{D}$, porcelain failure.

are the basic retention forces of prostheses (16), while the mechanical bonding force is principally generated by the mechanical interlocking of bonding agent on the rough surfaces of the prosthesis. The common methods used to improve the mechanical bonding force of a prosthesis include acid etching, sandblasting, laser, etc. (17-19). Previous studies have shown that acid etching failed to produce favorable roughening on zirconia porcelain surfaces due to their high inertia $(3,20,21)$. Sandblasting is currently an effective coarsening method recommended 


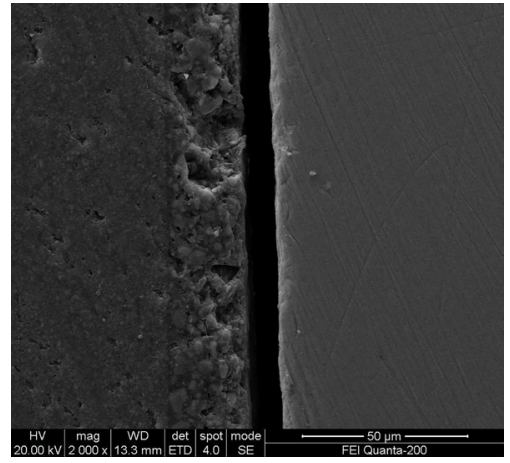

NN group

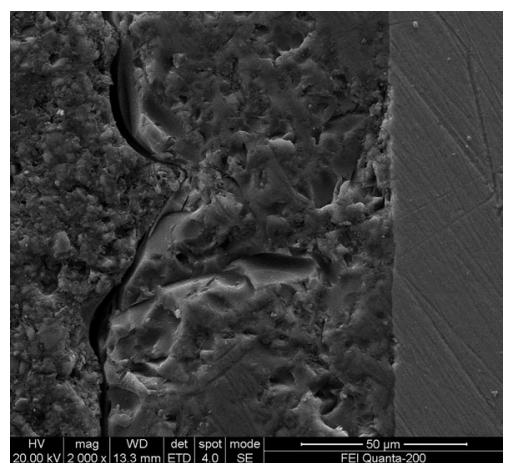

$\mathrm{PN}$ group

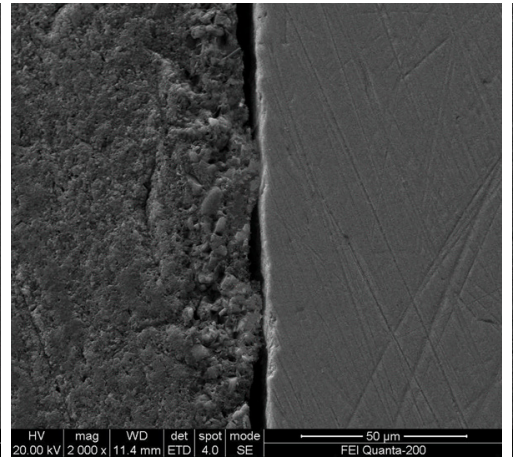

NM group

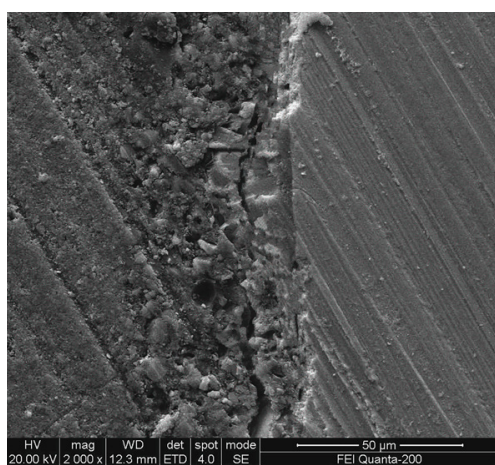

PM group

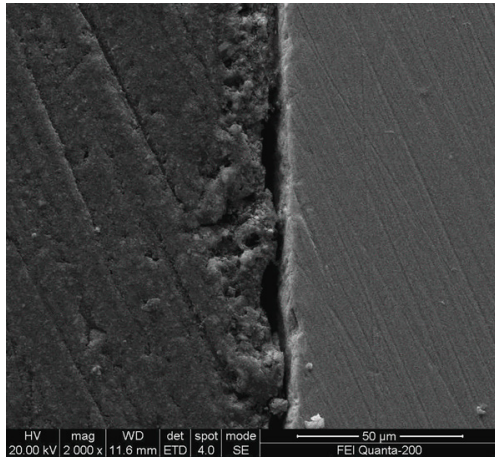

NC group

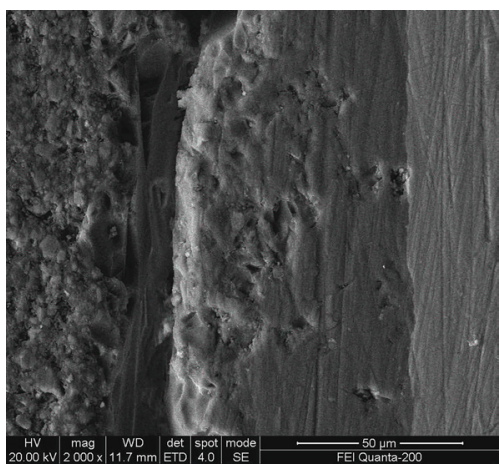

$\mathrm{PC}$ group

Figure 13 SEM scan graphs of the bonding interfaces of specimens in each group . SEM, scanning electron microscopy; NN, no porcelain sintering and agent; NM, no porcelain sintering + Monobond-S; NC, no porcelain sintering + Clearfil Repair; PN, porcelain sintering + no agent; PM, porcelain sintering + Monobond-S; PC, porcelain sintering + Clearfil Repair.

for zirconia porcelain, but it may include crystalline phase on the surface of the zirconia porcelain, producing microcracks on the surface of zirconia and impairing its mechanical strength (22). Alternatively, laser treatment works with an Erbium YAG (Er:YAG) laser to produce microbursts on the surface of zirconia porcelain, resulting in irregular roughness. However, there is still controversy over its effectiveness demonstrated through studies $(23,24)$. Therefore, the existing roughing techniques are of limited use for the treatment of zirconia ceramics and need to be further investigated. The surface morphology observation of the porcelain sintering group in the present study exhibits many voids with irregular shapes, which may be due to the formation of micropores in the veneer porcelain powder during high-temperature sintering, thus resulting in a rough surface that provides favorable mechanical retention for the resin bonding agent. Based on the SEM scan results of the bonding interface in the longitudinal section of the bonded specimen (Figures 4-10), large and thick resin tags were visible at the bonding interface of the porcelain sintering group $(\mathrm{P})$ stretching into the uneven structure of the porcelain block surface, also demonstrating that the uneven and rough surface produced by porcelain sintering provides the surface space for the formation of resin tags, thereby increasing the mechanical retention between resin bonding agent and porcelain block. The mechanical retention resulting from the rough surface of porcelain sintering is also the top cause of higher shear forces in the porcelain sintering group compared to the no porcelain sintering group when silane treatment is not performed. In addition, the silane coupling agent creates a wetting effect on the surface of the prosthesis, which facilitates the flow and penetration of bonding agent and the formation of resin tags, producing a microinterlocking effect.

Chemical bonding force is principally produced by covalent bonds produced by the treatment agent between prosthesis surface and bonding agent. Monobond-S is a one-component silane coupling agent with a functional monomer component called 3-(methacryloyloxy) propyltrimethoxysilane (3-MPS), which forms a Si-O-Si 
covalent bond with Si to produce chemical bonding force $(25,26)$. Clearfil Repair, however, is a two-component silane coupling agent containing two functional components, i.e., 10-methacryloyl dodecyl phosphate (MDP) and 3-MPS, which form covalent bonds with $\mathrm{Si}$ on the surface of the prosthesis. Moreover, MDP forms $\mathrm{P}-\mathrm{O}-\mathrm{Zr}$ covalent bonds with $\mathrm{Zr}$ to create a chemical bonding force $(27,28)$. Without porcelain sintering, no Si was observed in the NN group, and a large amount of $\mathrm{Zr}$ was visible in the energy spectrum, which facilitated the formation of chemical bonding by MDP on the zirconia surface, the principal reason why the shear force in the NC group was higher than in the other groups without porcelain sintering after Clearfil Repair treatment. In addition, one-component silane coupling agent Monobond-S was unable to form a chemical bonding force on the zirconia surface, while the NM group still had a higher shear force than that of the control group, thanks to the wetting effect of the silane coupling agent. The presence of a large amount of $\mathrm{Si}$ on the surfaces of the porcelain blocks of each porcelain sintering group in the energy spectrum analysis was due principally to the large amount of $\mathrm{SiO}_{2}$ in the IPS e.max Ceram powder for porcelain sintering, also indicating that porcelain sintering offers effective silicon coating on the surfaces of zirconia porcelain blocks, which constitutes the material basis for the formation of Si-O-Si covalent bonds on surfaces of porcelain blocks by 3-MPS. The chemical bonding force between 3-MPS and $\mathrm{SiO}_{2}$ may be the principal reason why the PM and PC groups with silane coupling agent were significantly better than the PN group without silane coupling agent. In addition, the failure of the bonding interface of the PC and PM groups was dominated by not only mixed failure but also cohesive failure of the bonding agent, which indirectly indicates that the bonding strengths of the PC and PM groups may contain strong chemical bonding forces.

In addition, energy spectral analysis revealed that no $\mathrm{Zr}$ was found in the porcelain sintering group, and the Clearfil Repair containing MDP was unable to form P-O$\mathrm{Zr}$ covalent bonds, but the shear strength of the PC group was still higher than the shear strength of the PM group, principally for the following reasons: First, the energy spectrum analysis revealed that the Si content of the NC group was $6.31 \%$ higher than the Si content of the NM group (1.39\%), indicating that the concentration of 3-MPS monomer in Clearfil Repair may be higher than the concentration of Monobond-S. Second, MDP has been reported to be a phosphate monomer, which could create an acidic environment that accelerates the hydrolysis of 3-MPS to increase its activity (29).

The interaction between porcelain sintering and treatment with silane coupling agents was found to be significant $(\mathrm{P}<0.05)$ according to factorial analysis, indicating a synergistic effect between sintering and the treatment with silane coupling agents to improve the strength and durability of the bond between zirconia porcelain and resin bonding agents. First, porcelain sintering produces many irregular micropores and bumps on the surface of the porcelain block, while the wetting effect of silane coupling agents on the surface of the porcelain layer has a synergistic effect on the mechanical bonding force. Second, porcelain sintering applies $\mathrm{SiO}_{2}$ in the porcelain powder on the surface of the zirconia porcelain, which constitutes the material basis for the formation of chemical bonding of 3-MPS in silane coupling agents on the surface of porcelain. Finally, after sintering, the $\mathrm{SiO}_{2}$ surface on the adhesive surface of the porcelain block forms hydroxyl groups $(-\mathrm{OH})$ that can create hydrogen bonds with the 3-MPS in silane coupling agents or hydroxyl groups (-OH) in MDP molecules (30), which interact with each other. The three above-noted interactions therefore suggest that the combination of sintering and silane coupling agent Monobond-S or Clearfil Repair is more effective in increasing the strength and durability of the bond between RelyX Unicem and zirconia porcelain block than the treatment with individual factors.

A comparison of the shear strength of the bonded specimens before and after thermal cycling demonstrated that the bond strength was significantly higher before thermal cycling than after $(\mathrm{P}<0.05)$, indicating that thermal cycling had a serious damaging effect on the bond strength between porcelain block and RelyX Unicem bonding agent, supported by the number of interface failure types increasing in all groups after thermal cycling. Possible causes of the effect of thermal cycling on the bond strength between resin bonding agent and porcelain block include the following. First, hydrogen bonds formed between the absorbent hydroxyl group $(-\mathrm{OH})$ produced on the surface of porcelain block and the hydroxyl group $(-\mathrm{OH})$ in 3-MPS or MDP molecules of the silane coupling agent are hydrophilic and weak and are prone to destruction by hydrolysis during thermal cycling (31). Second, the RelyX Unicem resin cement chosen for this experiment is a selfbonding cement; similar to glass ionomer cement, the composition of RelyX Unicem resin cement contains a large number of hydrophilic functional groups, and the polymeric components are frequently destroyed by hydrolysis after curing. Valandro et al. also found that the bond strength 
of a resin-cemented prosthesis was significantly reduced after 12,000 thermal cycles or 300 days of storage in a water bath (32). Finally, numerous papers have reported that the Si-O-Si covalent bonds formed by silane molecules 3-MPS on porcelain surfaces are susceptible to hydrolytic failure during thermal cycling (33). The combination of the three above-noted factors may lead to hydrolytic failure at the bonding interface of specimens during 5,000 thermal cycles in a water bath. The shear strengths of the PC group (with porcelain sintering) and the $\mathrm{NC}$ group (no porcelain sintering) were significantly lower after thermal cycling, but the shear strengths were still higher than in the other two groups; this difference was significant $(\mathrm{P}<0.05)$, showing that silane coupling agent Clearfil Repair not only improves the bonding performance of the zirconia porcelain surface but also resists artificial aging to a certain extent $(5,000$ thermal cycles), probably due to the strong bonding of the $\mathrm{P}-\mathrm{O}-\mathrm{Zr}$ covalent bond formed between MDP and the zirconia porcelain block surface and the decyl groups in MDP molecules being hydrophobic groups that protect the bonding interfaces from hydrolytic penetration.

\section{Acknowledgments}

Funding: The study was supported by Natural Science Foundation of Hunan Province (Project Nos. 2021JJ40965, 2012FJ3124, and 09JJ3029); Scientific Research Projects of Medical and Health Institutions of Longhua District, Shenzhen (Project No. 2021112); and Key Medical Disciplines in Longhua District, Shenzhen (MKD202007090212).

\section{Footnote}

Data Sharing Statement: Available at https://atm.amegroups. com/article/view/10.21037/atm-22-72/dss

Conflicts of Interest: All authors have completed the ICMJE uniform disclosure form (available at https://atm. amegroups.com/article/view/10.21037/atm-22-72/coif). The authors have no conflicts of interest to declare.

Etbical Statement: The authors are accountable for all aspects of the work in ensuring that questions related to the accuracy or integrity of any part of the work are appropriately investigated and resolved.

Open Access Statement: This is an Open Access article distributed in accordance with the Creative Commons
Attribution-NonCommercial-NoDerivs 4.0 International License (CC BY-NC-ND 4.0), which permits the noncommercial replication and distribution of the article with the strict proviso that no changes or edits are made and the original work is properly cited (including links to both the formal publication through the relevant DOI and the license). See: https://creativecommons.org/licenses/by-nc-nd/4.0/.

\section{References}

1. Bohner LO, Neto PT, Ahmed AS, et al. CEREC Chairside System to Register and Design the Occlusion in Restorative Dentistry: A Systematic Literature Review. J Esthet Restor Dent 2016;28:208-20.

2. Arslan Y, Karakoca Nemli S, Bankoğlu Güngör M, et al. Evaluation of biogeneric design techniques with CEREC CAD/CAM system. J Adv Prosthodont 2015;7:431-6.

3. Thammajaruk P, Inokoshi M, Chong S, et al. Bonding of composite cements to zirconia: A systematic review and meta-analysis of in vitro studies. J Mech Behav Biomed Mater 2018;80:258-68.

4. McLaren EA, Lawson N, Choi J, et al. New HighTranslucent Cubic-Phase-Containing Zirconia: Clinical and Laboratory Considerations and the Effect of Air Abrasion on Strength. Compend Contin Educ Dent 2017;38:e13-6.

5. Su N, Yue L, Liao Y, et al. The effect of various sandblasting conditions on surface changes of dental zirconia and shear bond strength between zirconia core and indirect composite resin. J Adv Prosthodont 2015;7:214-23. Erratum in: J Adv Prosthodont 2015;7:506.

6. Ahrari F, Boruziniat A, Alirezaei M. Surface treatment with a fractional $\mathrm{CO} 2$ laser enhances shear bond strength of resin cement to zirconia. Laser Ther 2016;25:19-26.

7. Akay C, Çakırbay Tanış M, Şen M. Effects of Hot Chemical Etching and 10-Metacryloxydecyl Dihydrogen Phosphate (MDP) Monomer on the Bond Strength of Zirconia Ceramics to Resin-Based Cements. J Prosthodont 2017;26:419-23.

8. Cakir-Omur T, Gozneli R, et al. Effects of Silica Coating by Physical Vapor Deposition and Repeated Firing on the Low-Temperature Degradation and Flexural Strength of a Zirconia Ceramic. J Prosthodont 2019;28:e186-e194.

9. Nagaoka N, Yoshihara K, Tamada Y, et al. Ultrastructure and bonding properties of tribochemical silica-coated zirconia. Dent Mater J 2019;38:107-13.

10. Lung CY, Kukk E, Matinlinna JP. The effect of silica- 
coating by sol-gel process on resin-zirconia bonding. Dent Mater J 2013;32:165-72.

11. Çakırbay Tanış M, Akay C, Şen M. Effect of selective infiltration etching on the bond strength between zirconia and resin luting agents. J Esthet Restor Dent 2019;31:257-62.

12. Valverde GB, Coelho PG, Janal MN, et al. Surface characterisation and bonding of Y-TZP following nonthermal plasma treatment. J Dent 2013;41:51-9.

13. Ozcan M, Vallittu PK. Effect of surface conditioning methods on the bond strength of luting cement to ceramics. Dent Mater 2003;19:725-31.

14. Nishigawa G, Maruo Y, Irie M, et al. Ultrasonic cleaning of silica-coated zirconia influences bond strength between zirconia and resin luting material. Dent Mater J 2008;27:842-8.

15. Cattani Lorente M, Scherrer SS, Richard J, et al. Surface roughness and EDS characterization of a Y-TZP dental ceramic treated with the CoJet ${ }^{\mathrm{TM}}$ Sand. Dent Mater 2010;26:1035-42.

16. Yi YA, Ahn JS, Park YJ, et al. The effect of sandblasting and different primers on shear bond strength between yttria-tetragonal zirconia polycrystal ceramic and a selfadhesive resin cement. Oper Dent 2015;40:63-71.

17. Menani LR, Farhat IA, Tiossi R, et al. Effect of surface treatment on the bond strength between yttria partially stabilized zirconia ceramics and resin cement. J Prosthet Dent 2014;112:357-64.

18. Zhao P, Yu P, Xiong Y, et al. Does the bond strength of highly translucent zirconia show a different dependence on the airborne-particle abrasion parameters in comparison to conventional zirconia? J Prosthodont Res 2020;64:60-70.

19. Tokar E, Polat S, Ozturk C. Repair bond strength of composite to Er,Cr:YSGG laser irradiated zirconia and porcelain surfaces. Biomed J 2019;42:193-9.

20. Dérand P, Dérand T. Bond strength of luting cements to zirconium oxide ceramics. Int J Prosthodont 2000;13:131-5.

21. Ural Ç, Külünk T, Külünk Ş, et al. The effect of laser treatment on bonding between zirconia ceramic surface and resin cement. Acta Odontol Scand 2010;68:354-9.

22. Shimoe S, Peng TY, Otaku M, et al. Influence of various airborne-particle abrasion conditions on bonding between zirconia ceramics and an indirect composite resin material. J Prosthet Dent 2019;122:491.e1-9.

23. Salem R, Naggar GE, Aboushelib M, et al. Microtensile Bond Strength of Resin-bonded Hightranslucency
Zirconia Using Different Surface Treatments. J Adhes Dent 2016;18:191-6.

24. Usumez A, Hamdemirci N, Koroglu BY, et al. Bond strength of resin cement to zirconia ceramic with different surface treatments. Lasers Med Sci 2013;28:259-66.

25. Öztürk-Bozkurt F, Toz T, Kara-Tuncer A, et al. Clinical Evaluation of Silorane and Nano-hybrid Resin Composite Restorations in Class II Cavities up to 3 Years. Oper Dent 2016;41:599-606.

26. Piascik JR, Swift EJ, Thompson JY, et al. Surface modification for enhanced silanation of zirconia ceramics. Dent Mater 2009;25:1116-21.

27. Lima RBW, Barreto SC, Alfrisany NM, et al. Effect of silane and MDP-based primers on physico-chemical properties of zirconia and its bond strength to resin cement. Dent Mater 2019;35:1557-67.

28. Tanış MÇ, Akçaboy C. Effects of Different Surface Treatment Methods and MDP Monomer on Resin Cementation of Zirconia Ceramics an In Vitro Study. J Lasers Med Sci 2015;6:174-81.

29. Akgungor G, Sen D, Aydin M. Influence of different surface treatments on the short-term bond strength and durability between a zirconia post and a composite resin core material. J Prosthet Dent 2008;99:388-99.

30. Han GJ, Kim JH, Cho BH, et al. Promotion of resin bonding to dental zirconia ceramic using plasma deposition of tetramethylsilane and benzene. Eur J Oral Sci 2017;125:81-7.

31. de Oyagüe RC, Monticelli F, Toledano M, et al. Influence of surface treatments and resin cement selection on bonding to densely-sintered zirconium-oxide ceramic. Dent Mater 2009;25:172-9.

32. Valandro LF, Ozcan M, Amaral R, et al. Microtensile bond strength of a resin cement to silica-coated and silanized InCeram Zirconia before and after aging. Int J Prosthodont 2007;20:70-2.

33. Ozcan M, Pfeiffer P, Nergiz I. A brief history and current status of metal-and ceramic surface-conditioning concepts for resin bonding in dentistry. Quintessence Int 1998;29:713-24.

Cite this article as: Zhao M, Zheng Y, Zhang JF, Ou X, Gao X, Zhang B, Cao Y. The effect of adhesive surface with porcelain sintering and two silane coupling agents on the adhesive properties of zirconia. Ann Transl Med 2022;10(2):87. doi $10.21037 /$ atm-22-72 